\title{
Pax9-deficient mice lack pharyngeal pouch derivatives and teeth and exhibit craniofacial and limb abnormalities
}

\author{
Heiko Peters, ${ }^{1}$ Annette Neubüser, ${ }^{2}$ Klaus Kratochwil, ${ }^{3}$ and Rudi Balling ${ }^{1,4}$ \\ ${ }^{1}$ GSF-Research Center for Environment and Health, Institute for M ammalian Genetics, 85764 N euherberg, Germany; \\ ${ }^{2}$ Department of Anatomy and Program in Developmental Biology, University of California, San Francisco, California \\ 94143-0452 USA; ${ }^{3}$ Institute of M olecular Biology, Austrian Academy of Sciences, A-5020 Salzburg, Austria
}

\begin{abstract}
Pax genes have been shown to play important roles in mammalian development and organogenesis. Pax9, a member of this transcription factor family, is expressed in somites, pharyngeal pouches, mesenchyme involved in crani ofacial, tooth, and limb development, as well as other sites during mouse embryogenesis. To analyze its function in vivo, we generated Pax9 deficient mice and show that Pax9 is essential for the development of a variety of organs and skeletal elements. Homozygous Pax9-mutant mice die shortly after birth, most likely as a consequence of a cleft secondary palate. They lack a thymus, parathyroid glands, and ultimobranchial bodies, organs which are derived from the pharyngeal pouches. In all limbs, a supemumerary preaxial digit is formed, but the flexor of the hindlimb toes is missing. Furthermore, craniofacial and visceral skeletogenesis is disturbed, and al teeth are absent. In Pax9-deficient embryos tooth development is arrested at the bud stage At this stage, Pax9 is required for the mesenchymal expression of Bmp4, Msx1, and Lef1, suggesting a role for Pax9 in the establishment of the inductive capacity of the tooth mesenchyme. In summary, our analysis shows that Pax9 is a key regulator during the development of a wide range of organ primordia.
\end{abstract}

[Key Words: Pax9; knockout; teeth; pal ate; thymus; parathyroids; skeleton]

Received M arch 9, 1998; revised version accepted A pril 30, 1998.

Pax9 is a member of a transcription factor family that is characterized by a common motif, the DNA-binding paired domain. This motif is encoded by the paired box, a conserved DNA region originally identified in Drosophila (Bopp et al. 1986; Baumgartner et al. 1987). In mammals, nine different Pax genes, which fall into four different subgroups, have been isolated (Walther et al. 1991; Wallin et al. 1993; Stapleton et al. 1993). Spontaneous as well as targeted mutations in several Pax genes have revealed that Pax genes perform essential functions during mammalian embryonic development. A common feature of Pax mutants is size reduction, malformation, or even the loss of specific organs, such as the immune system, brain, eye, nose, kidney, pancreas, as well as the skeleton and neural crest cell derivatives (for review, see Chalepakis et al. 1993; Dahl et al. 1997 and references therein).

The Pax9 gene is highly homologous to Paxl and is present in all vertebrates analyzed so far, including zebrafish, chick, mouse, and man (Stapleton et al. 1993; N eubüser et al. 1995; Peters et al. 1995; N ornes et al. 1996). During mouse development, Pax9 and Pax1 are

${ }^{4}$ Corresponding author.

E-MAIL balling@gsf.de; FAX 89 3187-3099. expressed in a similar, but not identical pattern in the sclerotomes, the ventromedial compartment of the somites that forms the vertebral col umn. Both genes al so exhibit overlapping expression patterns in the endodermally derived epithelium of the pharyngeal pouches, which give rise to the thymus, parathyroid glands, ultimobranchial bodies, eustachian tube, and tonsils. In the limbs, Pax1 and Pax9 transcripts localize to adjacent nonoverlapping mesenchymal domains whereas Pax9, but not Paxl, is widely expressed in neural crest-derived mesenchyme involved in craniofacial and tooth devel opment (Deutsch et al. 1988; Timmons et al. 1994; N eubüser et al. 1995, 1997).

The complex expression pattern of Pax9 during mouse embryogenesis suggests that it plays a role in the formation of various organs. To investigate its developmental function, we disrupted the murine Pax9 gene by homologous recombination in ES cells and introduced the re sulting mutation into the mouse germ line. Heterozygous mutants exhibit no obvious defects indicating that Pax9 is haploid sufficient. However, mice homozygous for the Pax9 deletion die shortly after birth and exhibit a wide range of developmental defects. They lack the derivatives of the third and fourth pharyngeal pouches, that is, the thymus, parathyroid glands, and ultimobranchial 
bodies. In addition, al I teeth are absent, and our analysis suggests that BM P4-mediated signal ing in the tooth mesenchyme is affected in Pax9-deficient embryos. The secondary palate is cl eft and a variety of skel etal abnormalities affecting the head and the visceral skeleton develop in the absence of Pax9. Furthermore, supernumerary digits are formed and the flexor of the hindl imb toes is missing. Taken together, our analysis reveals essential roles for Pax9 during the development of a variety of organs derived from endoderm, mesoderm, and neural crest.

\section{Results}

Generation of Pax9-deficient mice

A functional null allele of Pax9 was created by replacement of the endogenous start codon as well as the exon containing the paired box with a promoterless Escherichia coli ATG-lacZ-poly(A) cassette and the PGK-neo gene (Fig. 1A). ES cells carrying the mutated allele, Pax9lacz, were introduced into mouse blastocysts, and germ-line transmission was obtained from two chimeras (Fig. 1B,C). Heterozygous Pax ${ }^{\text {lacz }}$ mice are viable, fertile, and do not exhibit any obvious abnormalities. Heterozygous matings gave rise to all expected genotypes at Mendelian frequency $(19.7 \%+1+, 57.2 \%+-, 23.1 \%-t-$; $\mathrm{n}=173$ ), indicating that lack of Pax9 protein, which was confirmed by Western blot analysis (Fig. 1D), does not result in embryonic lethal ity. In contrast, newborn Pax9deficient mice exhibit gasping respirations, develop a bloated abdomen (Fig. 1E), and die within few hours.

\section{Expression of the Pax $9^{\text {lacz }}$ allele}

The normal development of heterozygous Pax9lacz mutant mice all owed us to use the lac $Z$ gene as a sensitive reporter of Pax9 promoter activity during mouse embryogenesis. X-gal staining of heterozygous Pax $9^{l a c z} \mathrm{em}$ bryos recapitulated the Pax9-expression pattern obtained previously by RNA in situ hybridization studies ( $\mathrm{Neu}$ büser et al. 1995; A. Neubüser, unpubl.). At E9.0, Pax9lacz expression was restricted to the pharyngeal pouches (Fig. 2A). At E10.5, additional staining was detected in the somites, in the developing medial nasal process, and at the tip of the tail (Fig. 2B, and data not shown). Cross sections showed that in the somites, the expression is restricted to the ventrolateral part of the sclerotomes whereas, in the tail region, it is confined to the tail gut (Fig. 2B, and data not shown). At E12.0, the mesenchyme of the maxillary and mandibular arches as well as the nasal mesenchymes strongly express Pax9lacZ (Fig. 2C). At E13.5, expression was found in the midbrain, facial mesenchyme, middle ear, pharyngeal epithelium and its derivatives, esophagus, limbs, vertebral column, intercostal mesenchyme, tail gut, and ventral tail mesenchyme (Fig. 2D). In the midbrain, Pax9 $9^{l a c z}$ expression was detected in the tegmentum and in the developing mammillary bodies (Fig. 2E). At E16.5, Pax $9^{\text {lacz }}$ is expressed in the salivary glands, tongue, and in the mesenchyme of all teeth (Fig. 2F,G,H). At the

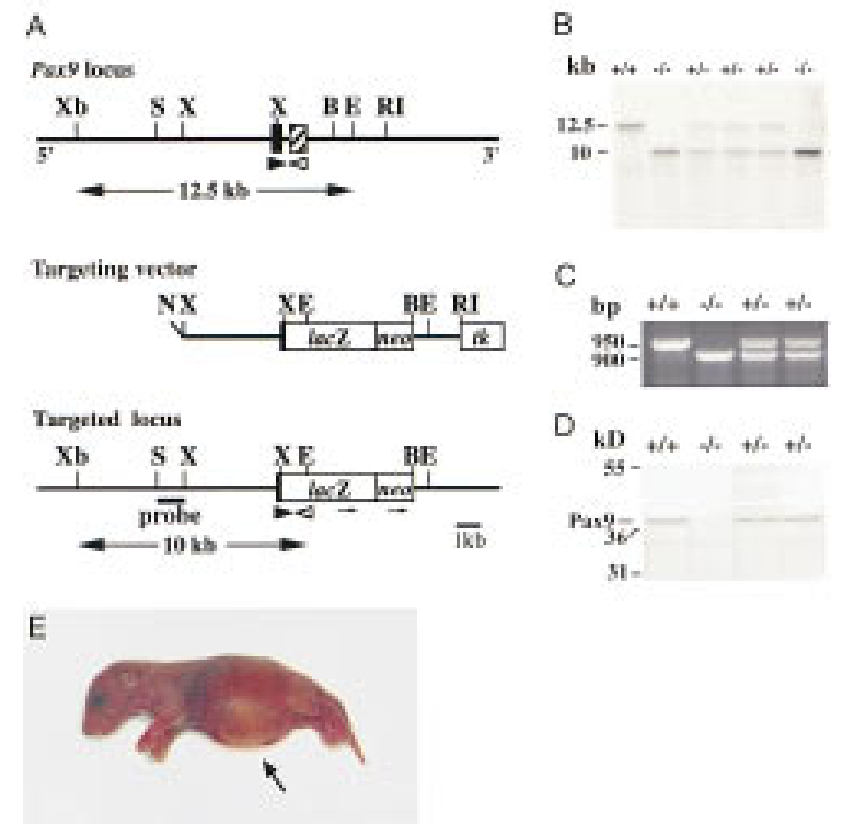

Figure 1. Generation of Pax9-deficient mice. (A) Structure of wild-type locus, targeting vector, and disrupted Pax9 allele. The ATG-lacZ-neo cassette was fused to the ATG-containing exon (black box) of Pax9, thereby deleting two thirds of the Pax9 coding sequence including the DN A binding region encoded by the paired box (hatched box). HSV-TK was ligated to the $3^{\prime}$ arm of the targeting vector and was used as a negative selection marker. The 5' external probe used for genomic Southern blot analysis is shown as a black line. Solid arrowheads indicate the primer located in the ATG-containing exon; open arrowheads indicate allele-specific primers that were used for genotyping. (B) BglII; (E) EcoRV; (N) Notl; (RI) EcoRI; (S) Sall; (X) Xmal; (Xb) Xbal. (B) Southern analysis of embryos obtained by heterozygote matings. (C) PCR assay of Paxglacz mutant embryos. Yolk sacs of embryos were used for isolation of genomic DNA. PCR was performed with three primers shown in $A$ in a single reaction to distinguish between the wild-type (950 bp) and the transgenic (900 bp) locus. (D) Western blot analysis of Pax9lacz mutant embryos. The antiserum 281-IV detects a Pax9-specific 38$\mathrm{kD}$ band only in protein extracts prepared from vertebral columns of wild-type and heterozygous embryos (E13.5). (E) Homozygous Pax9lacz mutant shortly after birth. The mutants are born alive but die within a few hours. During that time, they exhibit gasping respirations and develop a bloated abdomen (arrow).

same stage, the thymus, parathyroid glands, and ultimobranchial bodies, as well as the epithelia of the Iarynx, esophagus, and forestomach were stained (Fig. 2l).

In the following description, we refer to homozygous Pax $9^{l a c z}$ mutant mice as mutants whereas controls are either wild type or heterozygous.

Formation of a cleft secondary palate in Pax9-deficient mice

Inspections of the head revealed that all mutants have a cleft secondary palate at birth, thus providing a possible explanation for the severe respiratory problems observed 
A

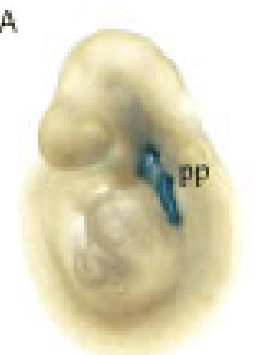

B

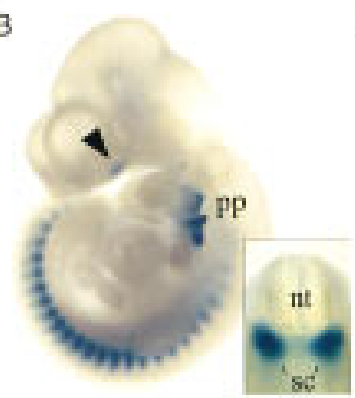

D

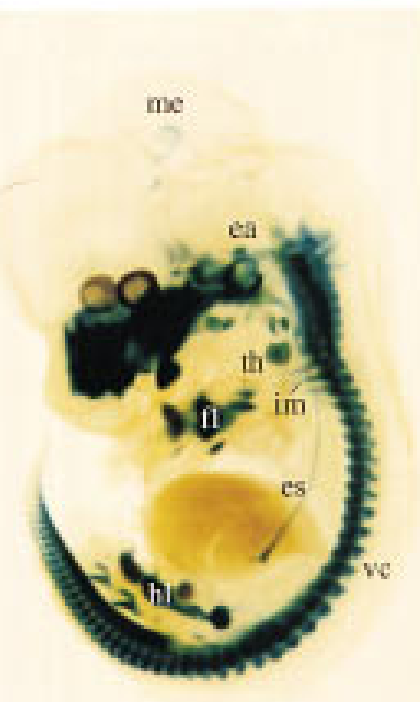

E
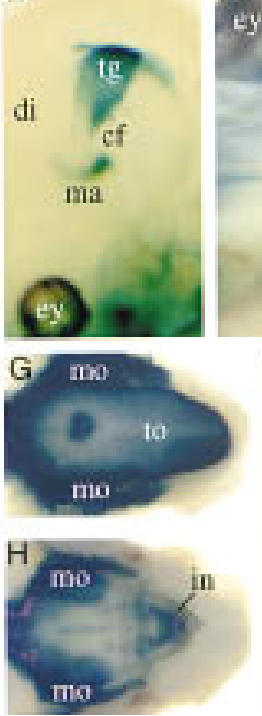

C

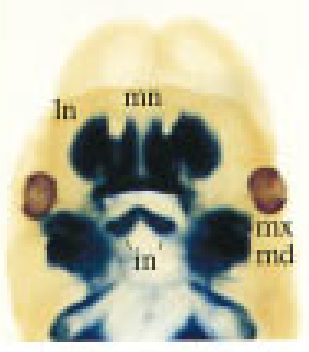

ea

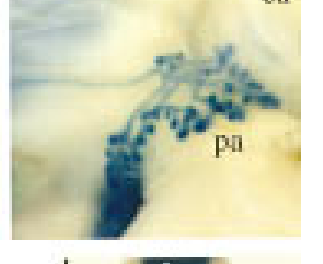

।

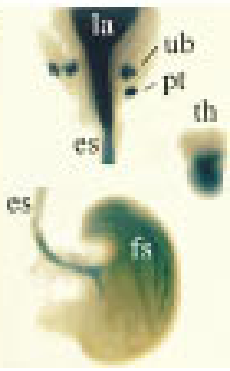

Figure 2. Expression of the Paxglacz allele during mouse devel opment reveal ed by whole-mount X-gal staining of heterozygous Paxglacz embryos. (A) Pax9lacZ expression at E9.0 is restricted to the pharyngeal pouches (pp). (B) At E10.5, additional staining is detectable al ong the body axis and in the facial mesenchyme (arrowhead). The expression in the somites is restricted to the sclerotomes (sc in insert). (C-E) Embryos were cleared with benzylbenzoate/ benzylalcohol after X-gal staining. (C) At E12.0, mesenchymes of the nasal processes as well as of the maxillary $(\mathrm{mx})$ and mandibular $(\mathrm{md})$ arches are strongly stained. In addition, expression of Pax $9^{\text {lacz }}$ is seen in the region of the devel oping lower incisors (in). (D) At E13.5, a number of structures express Paxglacz including facial mesenchyme, ear (ea), thymus (th), esophagus (es), forel imb (fl), hindlimb (hl), vertebral column (vc), intercostal mesenchyme (im), and a small domain of the mesencephal on (me). (E) In the mesencephalon, Pax9lacz expression is restricted to the tegmentum ( $\mathrm{tg}$ ) and the mammillary bodies (ma) at E14.5. (F-I) Pax9lacz expression at E16.5. (F) Lateral view of the head. The branching ducts of the parotis gland (pa) are Pax $9^{\text {lacz }}$ positive. (G) In the lower jaw, Paxglacz expression was found in the tongue (to) and in the region of the developing molars $(\mathrm{mo}) .(\mathrm{H})$ Similarly, the expression in the upper jaw is strongest in the region of the developing teeth. (I) The derivatives of the foregut endoderm express Pax9 ${ }^{1 a c z}$. Expression was detected in the epithelium of the Iarynx (la), esophagus (es), and forestomach (fs), but also in the thymus (th), parathyroid glands (pt), and ultimobranchial bodies (ub). (cf) Cephal ic flexure; (di) diencephal on; (ey) eye; (In) lateral nasal process; $(\mathrm{mn})$ medial nasal proces; $(\mathrm{nt})$ neural tube. in those pups. Skeletal stainings reveal ed that both maxillary and pal atine shel ves are cl eft, allowing di rect view to the presphenoid and into the nasal cavity (Fig. 3G).

To examine the developmental course of cleft palate formation, different stages of embryonic development were analyzed histologically. Secondary palate formation starts around E12.0 with a bilateral outgrowth from the maxillary portions of the first branchial arch. The palatal processes grow al ong the side of the tongue and later elevate and fuse above the dorsum of the tongue (Greene and Pratt 1976). At E12.0, the pal atal shelves of mutant embryos appear normal compared to those of control embryos (data not shown). In contrast, at E13.5 the shelves of mutant embryos reveal ed an abnormally broadened shape and lacked characteristic indentations at their ventrolateral sides (Fig. $3 \mathrm{C}$ ). At this stage, Pax9 is normally expressed not only in the palatal shelves, but also in the mesenchyme of the mandibular arch facing the pal atal shel ves (Fig. 3A). This regi on of the mandible is also abnormally shaped in the mutant (Fig. $3 C$ ). The aberrant morphol ogy of the palatal shelves suggests that in mutant embryos, the simultanous elevation, a prerequisite for normal palate development, is mechanically hindered. In fact, we have observed mutant embryos in which shelf elevation has occurred only on one side (Fig. $3 E)$. Therefore, Pax9 is not necessary for the capability of the shelves to elevate but is required to regulate their shape at a critical stage of secondary palate formation.

Tooth development is arrested at the bud stage in the absence of Pax9

Previous studies have demonstrated that, in the mandibular arch, Pax9 is expressed in prospective tooth mesenchyme prior to any morphological signs of odontogenesis and that Pax9 expression is restricted to the mesenchymal compartment of the developing teeth between E10.0 and E16.5 (Fig. 3A; Neubüser et al. 1997; and A. N eubüser, unpubl.). Inspections of both jaws of newborn Pax9 mutant mice reveal ed the absence of all teeth. To investigate at which stage tooth devel opment is affected, we followed molar development in mutant and control embryos in serial histological sections. By morphological criteria, tooth development is initiated normally in the mutant and is indistinguishable from controls until E12.5 (data not shown). At E13.5, the dental epithelia of both mutants and controls have invaginated to form epithelial buds, but the condensation of mesenchymal cells around the bud is less prominent in the mutant (Fig. 4A,B). At E14.5, tooth development has reached the cap stage in wild-type embryos whereas, in mutants, only a rudimentary bud was present (Fig. 4C,D). Examination of 


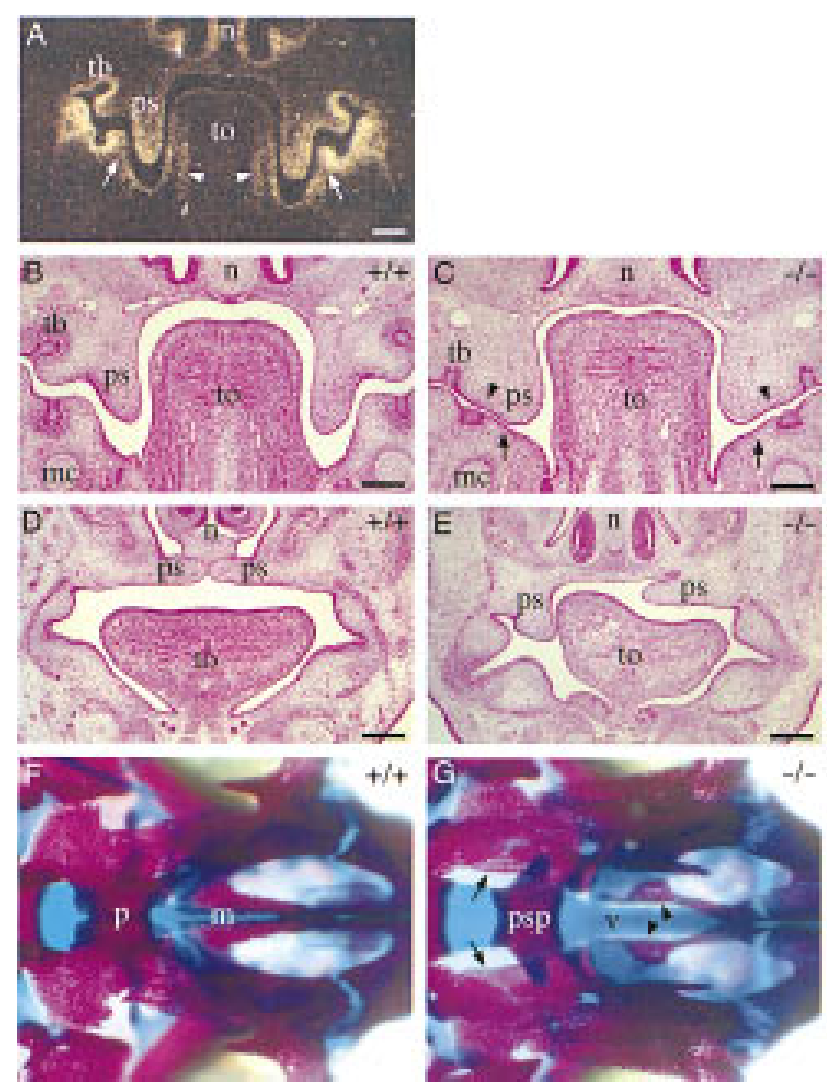

Figure 3. Development of cleft secondary palate in homozygous Paxglacz mutant embryos. (A-C) Coronal section of the head at the level of the developing molars at E13.5. (A) Section hybridized with a Pax9-specific RN A probe. Pax9 is expressed in the mesenchymes of the nose ( $n)$, palatal shelves (ps), and in the mesenchyme underlying the epithelial tooth bud (tb). N ote al so the expression of Pax9 in the mandibular arch mesenchyme facing the palatal shelves (arrows) and in the lateral tongue (to) mesenchyme (arrowheads). (B) H/E-stained section of a wildtype embryo. (C) H/E-stained section of a homozygous Paxglacz embryo. The palatal shelves are present but abnormally broadened. Both lateral indentations of the palatal shelves (arrowheads) as well as the mesenchymal outgrowth (arrows) facing the indentations are absent. (D,E) H/E-stained coronal sections anterior to the devel oping mol ars at E14.5. (D) In wild-type embryos, palatal shelves have elevated and are in the process of fusion. (E) In Pax9-deficient embryos, bilateral shelve el evation is impaired. $(F, G)$ Skel etal stainings of the secondary palate of newborn mice. Anterior is to the right. $(F)$ In wild-type mice the bony elements of the palatine $(p)$ and the maxillary $(m)$ shelves are almost fused. (G) In homozygous Paxglacz mutants both shel ves are absent allowing direct view to the vomer (v) and the presphenoid (psp). The borders of the open maxillary and palatine shelves are indicated by arrowheads and arrows, respectively. (mc) M eckels cartilage. Bars, $200 \mu \mathrm{m}$.

later stages revealed that tooth development never proceeded beyond the bud stage (data not shown). Thus, Pax9 function is required in all developing teeth before or at the bud stage (E13.5).

T ooth development is characterized by a series of interactions between dental epithelium and mesenchyme.
Odontogenesis is induced by the epithelium around E10.0 whereas between E11.5 and E13.5, the mesenchyme becomes the dominating tissue ( $\mathrm{M}$ ina and Kollar 1987; Lumsden 1988; for review, see Thesl eff and Sharpe 1997). Although the tooth buds of Pax9-deficient embryos appeared histologically normal, they may al ready be affected by the absence of Pax9 expression before E13.5. To investigate whether the potential of epithelial morphogenesis is irreversibly lost in the tooth buds of Pax9-deficient embryos, we performed tissue recombination experiments. Epithelia and mesenchymes from tooth germs of normal and Pax9-deficient embryos at E13.5 were separated, reassociated in both combinations and were then grafted under kidney capsules of adult mice. Combinations of Pax9-deficient mesenchyme and normal epithelium (both E13.5) formed epithelial cysts only and failed to form teeth ( $n=6$, data not shown). However, combinations of normal mesenchyme with Pax9-deficient epithelium yiel ded at least one tooth per graft $(n=6)$. Furthermore, tooth morphogenesis was similar to that of control combinations, and both tissues completed cytodifferentiation including the secretion of dentin and enamel (Fig. 4E,F). These results show that Pax9 function is required in the mesenchyme but also demonstrates that all consequences of Pax9 deficiency on epithelial development before E13.5 can be overcome by a wild-type mesenchyme isolated at the bud stage.

Pax9 is required for the mesenchymal expression of Bmp4, M sx1, and Lef1 at a critical stage of tooth development

At the bud stage, the tooth mesenchyme induces the formation of the epithelial enamel knot, a signaling center that regulates tooth development at the cap stage (Vaahtokari et al. 1996). Recently, BM P4 was shown to be involved in this induction (Jernvall et al. 1998). At E13.5, Bmp4 is expressed in tooth mesenchyme, and recombinant BM P4 was found to induce mesenchymal expression of Msx1, Lef1, and Bmp4 itself (Vainio et al. 1993; Kratochwil et al. 1996). Conversely, mesenchymal Bmp4 expression depends on Msxl (Chen et al. 1996), but not on Lef1 (Kratochwil et al. 1996), two other genes required for tooth development to proceed beyond the bud stage (Satokata and M aas 1994; Van Genderen et al. 1994). To determine whether Pax9 is involved in the regulation of these genes, we analyzed the expression of Bmp4, Msx1, and Lef1 in tooth primordia of mutant embryos. At E12.0, the expression patterns of all three genes in mutant embryos were indistinguishable from those of wild-type embryos (data not shown). At E13.5, however, Bmp4 expression was barely detectable in the mesenchyme of Pax9lacz mutant embryos (Fig. 4H). At the same stage, the mesenchymal expression of Msxl and Lef1 was found to be substantially down-regulated (Fig. 4J,L). At E14.5, both Msx1 and Lef1 transcripts were present in the tooth mesenchyme of controls but were almost undetectable in the mutants (data not shown). These results demonstrate that, at the bud stage, Pax9 is required for the maintenance of Bmp4 expression in the 


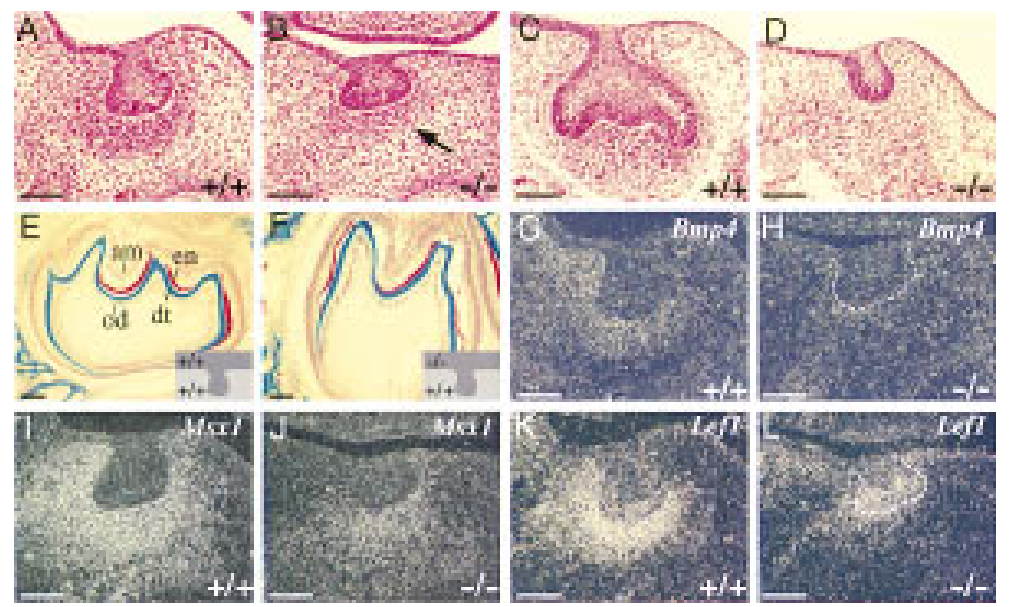

Figure 4. Arrest of tooth devel opment in homozygous Pax9lacz mutant embryos. (A-D) H/E-stained coronal sections at the level of the developing molars. (A) At E13.5, mesenchymal cells condense around the epithelial tooth bud. (B) At the same stage, in the homozygous Paxglacz mutant embryo, a tooth bud has formed but cellular condensation is reduced (arrow). (C) At E14.5, tooth development has reached the cap stage in the wild-type embryo. (D) In contrast, loose mesenchyme underlying a rudimentary bud is present in the mutant littermate. $(E, F)$ Tooth development in experimental combinations of dental tissues isolated at E13.5. (E) Combinations of wild-type dental mesenchyme and wildtype epithelium yielded well-developed teeth in subrenal grafts. Typical cytodifferentiation was observed including the presence of dentine (dt) secreted by odontoblasts (od), and enamel (en) secreted by amel oblasts (am). (F) A similar result was obtained with normal mesenchyme combined with Pax9-deficient dental epithelium. In contrast, combinations of Pax9-deficient mesenchyme and normal epithelium failed to form teeth (data not shown). (G-L) In situ hybridization of mesenchymal markers during molar devel opment of normal $(G, I, K)$ and Pax9 mutant $(H, J, L)$ embryos at E13.5. (G) At E13.5, Bmp4 is expressed in the mesenchyme underlying the epithelial tooth bud. In the absence of Pax9 $(\mathrm{H}), \mathrm{Bmp} 4$ transcripts are barely detectable. (I) Msxl expression is strong in the tooth mesenchyme and substantially reduced in the absence of Pax9 (J). (K) In wild-type embryos, both the mesenchyme and the margin of the tooth bud epithelium express Lef1. (L) In the absence of Pax9, the mesenchymal expression of Lef1 is reduced whereas the expression in the epithelium is not affected. For clarity, the borders of the tooth buds are outlined by broken lines in $\mathrm{H}$ and L. Bars, $100 \mu \mathrm{m}$.

dental mesenchyme, which provides a possible explanation for the subsequent down-regulation of Msxl and Lef1 expression.

Pax9 is essential for the development of thymus, parathyroid glands, and ultimobranchial bodies

To investigate the role of Pax9 during the formation of organs derived from the pharyngeal pouches, serial histological sections of the neck and upper trunk region of mutant embryos (E14.5) were anal yzed. N o devel opmental abnormalities were found in the derivatives of the first and second pouches (data not shown). In contrast, the primordia of thymus and parathyroid glands, both derivatives of the third pharyngeal pouches, as well as the ultimobranchial bodies, which are derived from the fourth pouches, are absent in Pax9-deficient embryos (Fig. 5D,J,N). To determine the onset of phenotypic abnormalities during pharyngeal pouch development, we used X-gal staining of heterozygous and homozygous Pax9'acz mutant embryos to label the pharyngeal pouch epithelia.

At E10.0, the pharyngeal pouches, outlined by Pax9lacz-expression appear normal in homozygous mutant embryos (Fig. 5F) indicating that the initial phase of pharyngeal pouch formation is not disturbed. In contrast, at E11.5, development of the third and fourth pharyngeal pouches is retarded in mutant embryos (Fig. $5 \mathrm{H}$ ). Subsequently, these pouches do not separate as epithelial buds to form the early rudiments of thymus, parathyroids, and ultimobranchial bodies (Fig. 5J). At E14.5, the primordia of thymus, parathyroid glands, and ultimobranchial bodies were clearly visible in heterozygous embryos (Fig. $5 \mathrm{M}$ ), whereas none of these organs could be detected in homozygous mutants (Fig. 5N). Because the fourth pha- ryngeal pouches are difficult to identify on histological sections, we used HoxB1 expression as an early marker of the fourth pharyngeal pouch epithelium (Frohman et al. 1990; Manley and Capecchi 1995). Immunostaining reveal ed that at E10.0, expression of HoxB1 in mutant embryos was indistinguishable from that of controls (Fig. 5K,L). By E11.0, however, HoxB1 expression in the mutants was strongly reduced (Fig. 5P), supporting our conclusion that ultimobranchial bodies are not formed in the absence of Pax9.

Pax9 is required for skeletal development of skull and larynx

In situ hybridizations to horizontal sections of the head (E14.0) showed that Pax9 is expressed at the base of the developing skull (Fig. 6B). Skel etal preparations revealed the absence of the processus al aris in the skull of newborn mutants (Fig. 6D). In addition, the pterygoid process is severely malformed and, in most cases, the tympanic ring is greatly reduced in size (Fig. $6 \mathrm{D}, \mathrm{H})$. In both jaws, the al veolar ridges, which normally surround mol ars and incisors, are missing (Fig. 6K and data not shown). M oreover, the coronoid process, a dorsal extension of the mandible, is absent (Fig. 6K).

At E14.0, expression of Paxglacz was detected in the mesenchyme surrounding Reicherts cartilage (Fig. 6E). In most mutants, Reicherts carti lage was absent (Fig. 6F,H); however, in a few cases (3/26), it was extended and connected to the hyoid bone (Fig. $6 \mathrm{I}$ ). In the laryngeal cartilages of homozygous mutants, both the greater and the lesser horn of the hyoid bone are mal formed. In addition, the thyroid cartilage is broadened and lacks two processes normally connecting thyroid and cricoid cartilage (Fig. 6M ). Remarkably, we were not able to detect Pax9 
Figure 5. Absence of thymus, parathyroid glands, and ultimobranchial bodies in Pax9deficient mice. (A-D) H/E-stained transverse sections of the neck region at E14.5. (A) Two thymic lobes (th) are present in the wild-type embryo. (B) At the same level, Pax9-deficient embryos are completely devoid of the thymus. Thymic rudiments were also not found in other regions of the neck and upper trunk (data not shown). (C) The parathyroid glands (pt) are attached to the thyroid gland (thy) in wild-type embryos and are absent in homozygous Paxglacz mutant embryos (D). (E-J,M,N) Ventral view of cleared whole-mount $X$-gal stainings of the pharyngeal pouches and their derivatives in Pax9 ${ }^{\text {lacz }}$ mutant embryos. (E) In heterozygous Pax9lacz mutant embryos at E10.0, Pax9lacz is expressed in all four pharyngeal pouches (I-IV). (F) At the same stage, the third and fourth pharyngeal pouches are also present in homozygous Paxglacz mutant embryos. (G) The third and fourth pharyngeal pouches have started to separate from the pharynx epithelium at E11.5. $(\mathrm{H})$ In homozygous Paxglacz mutants, the third (open arrowheads) and fourth (filled arrowheads) pouches
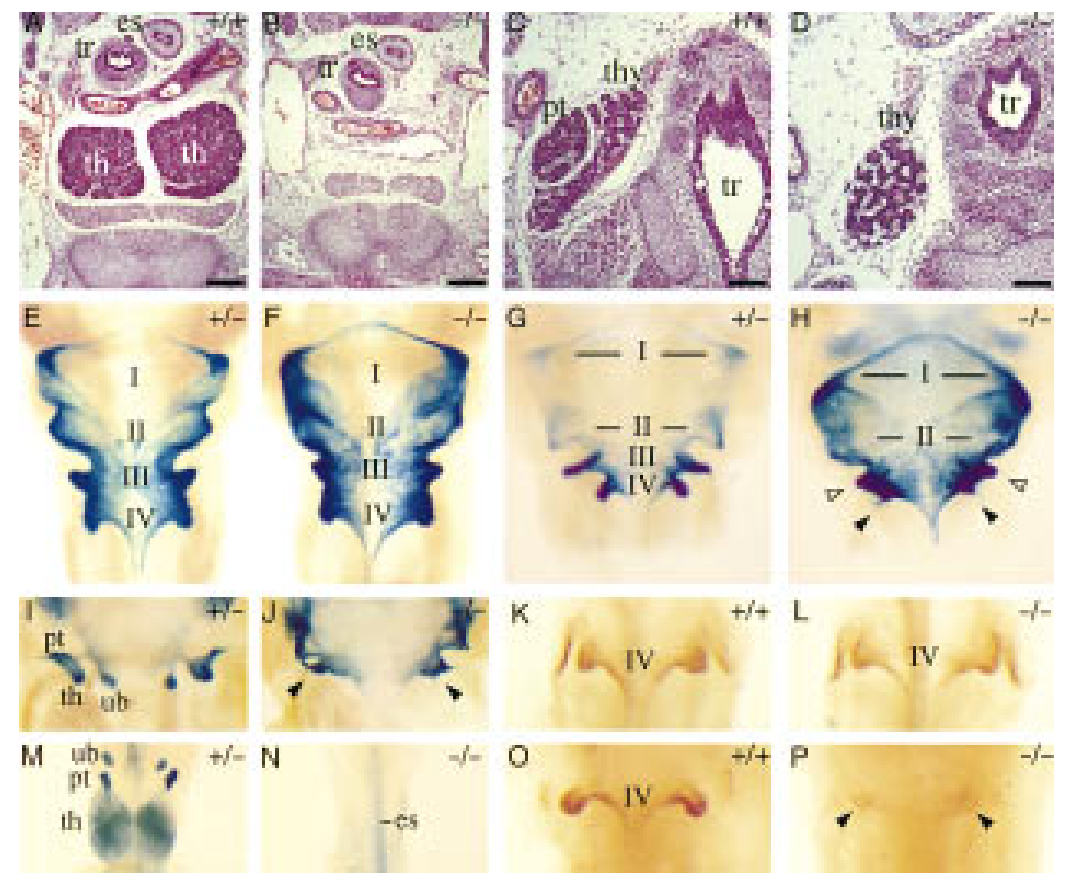
are retarded at E11.5. (I) Around E12.0, individual organ primordia of thymus (th), parathyroid glands (pt), and ultimobranchial bodies (ub) become visible as epithelial buds, which are absent in homozygous Pax9lacz mutants (arrowheads in J). (M) Pax9lacz expression is maintained in the primordia of thymus, parathyroid glands, and ultimobranchial bodies of heterozygous Pax9lacz mutant embryos at E14.5, whereas these organs are absent in homozygous Paxglacz mutant embryos (N). (K,L,O,P) Ventral view of the fourth pharyngeal pouches of whole-mount embryos stained with HoxB1-specific antibodies. At E10.0, the epithelium of the fourth pouches expresses HoxB1 in both wild-type (K) and Pax9-deficient (L) embryos. (O) At E11.5, HoxB1 expression is continued in the fourth pharyngeal pouches. (P) A weak expression of HoxB1 (arrowheads) is detectable in the epithelial remnant of the fourth pharyngeal pouches in homozygous Pax $9^{\text {lacz }}$ mutant embryos. (es) Esophagus; (tr) trachea. Bars, $200 \mu \mathrm{m}$.

expression in the laryngeal cartilages at any stage (E12.5E18.5; data not shown).

\section{Skel etal defects of the limbs}

In the developing limbs, expression of Pax9 is first detectable at E11.5 in the anterior mesenchyme of the limb bud (N eubüser et al. 1995; Fig. 7A). Subsequently, the Pax9 expression domains el ongate and are found in the anterior mesenchymes of the zeugopods of fore- and hindlimb at E12.5, as shown by X-gal staining of heterozygous Pax9lacz mutants (Fig. 7B,C). Pax9'acZ is also expressed in the region of the developing metatarsals and metacarpals (Fig. 7B,C), suggesting that Pax9 is involved in pattern formation at different sites of the developing limb.

Skel etal preparations reveal that homozygous Paxglacz mutants develop preaxial di git duplications in both foreand hindlimbs. In the hindlimb, a small supernumerary toe is formed (Fig. 7G). In addition, the ossification center of the first phal ange is severely reduced in the first toe, and the anterior tarsals are abnormally broadened and fused. The phenotype is less severe in the foreli $\mathrm{mb}$ in which the supernumerary digit does not separate from the thumb (Fig. 7E). Externally, the first signs of limb mal formations were detected around E13.5 as a thicken- ing of the anterior-proximal limb mesenchyme (data not shown).

To examine the limb abnormalities in more detail, we analyzed cross sections of X-gal stained hindlimbs (E14.0). At the mid-level of the metatarsals, Paxglacz expression was seen between individual metatarsals in both control and mutant embryos (Fig. 8C,D). At this level, no abnormalities were detected in the mutants. In the proximal region of the metatarsals of control embryos, Pax9lacz-expression is sharply restricted to the region of the devel oping first metatarsal and ventrally to it. In contrast, in the mutants the expression was found in a wide area of undifferentiated mesenchyme where the additional digit is formed (Fig. 8E,F). This result indicates that Pax9 regulates pattern formation of the anterior skeletogenic mesenchyme, and that this process in turn is required to restrict Pax 9 expression to the correct sites. In the absence of Pax9, additional mesenchyme is formed in the anterior limb regi on, which later differentiates into supernumerary di gits and ectopic cartilage in the middle hand or foot.

At the level of the tibia, Pax $9^{l a c z}$ expression was found to be proximally extended in homozygous mutants (Fig. 8B). Cross sections of controls reveal ed that in this region Paxglacz is expressed in noncartilaginous tissues including two developing tendons (Fig. 8G,I). These ten- 

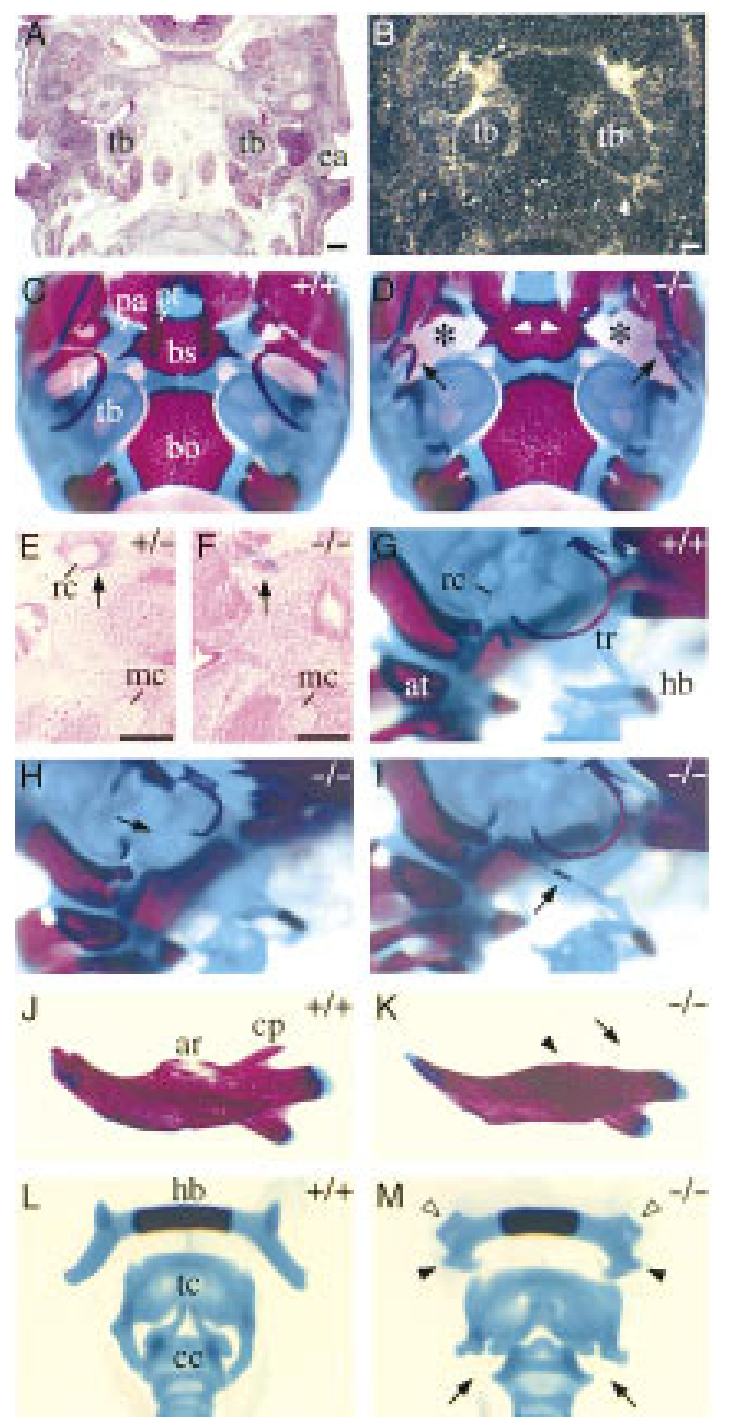

Figure 6. Craniofacial abnormalities in homozygous Paxglacz mutant mice. (A) H/E-stained section of the base of the developing skull at E13.5. (B) Parallel section to A hybridized with a Pax9-specific RNA probe. Expression of Pax9 is found in the mesenchyme surrounding the tympanic bulla (tb). (C,D) Ventral view of the skull stained with alizarin red and alcian blue. Anterior is at the top and the lower jaw has been removed. (C) Skeletal elements of the posterior half of the skull. (D) In homozygous Pax9 ${ }^{\text {lacz }}$ mutant mice the processus alaris [(pa) asterisks] is absent and the pterygoid process [(pt) arrowheads] is malformed. $N$ ote also the severely malformed tympanic rings (arrows). (E) Weak Pax9lacz expression is detectable in a heterozygous Pax9lacz mutant at E14.0 in the mesenchyme surrounding Reicherts cartilage ( $(\mathrm{c})$. (F) In most homozygous Pax $9^{\text {lacz }}$ mutants Reicherts cartilage is absent, however, Pax9lacz expression is found in a region in which it normally develops (arrow). (G-M) Skeletal staining of different skeletal elements of newborn mice. $(G, H, I)$ Lateral view of Reicherts cartilage and middle ear. Anterior is to the right. (G) N ormal shape of Reicherts cartilage $(\mathrm{rc})$ in a wild-type newborn mouse. $(\mathrm{H})$ In most cases, Reicherts cartilage is not formed in the absence of Pax9 (arrow). (I) In few homozygous Pax ${ }^{\text {lacz }}$ mutants, Reicherts cartilage is present but abnormally el ongated and fused to the hyoid bone (hb). The arrow points to the ossification center of Reicherts cartilage. $\mathrm{N}$ ote also that in this specimen the tympanic ring (tr) is not affected. (J) Normal appearance of the lower jaw. (K) In homozygous Pax $9^{\text {lacz }}$ mutants the al veol ar ridge [(ar) arrowhead] and the coronoid process [(cp) arrow] are absent. (L) Dorsal view of the laryngeal cartilages of normal mice. (M) In the absence of Pax 9 both lesser (open arrowheads) and greater (solid arrowheads) horns of the hyoid bone (hb) are malformed. The thyroid cartilage (tc) of the mutant is broadened and lacks lateral processes normally connecting thyroid and cricoid cartilage [(cc) arrows]. (at) Atlas; (bo) basioccipital bone; (bs) basisphenoid; (ea) ear; (mc) Meckels cartilage. Bars, $200 \mu \mathrm{m}$. dons belong to a group of three muscles located at the ventral side of the tibia (Fig. 8M). Cross sections through the leg of mutant embryos not only confirmed the ectopic expression of Pax $9^{l a c z}$ ventrally to the tibia, but al so reveal ed the absence of one of the three tendons (Fig. $8 \mathrm{H}, \mathrm{J})$. Sections through the lower leg of newborn mice indicated that the missing tendon bel ongs to the musculus flexor digitorum, the flexor of the second to fifth toes (Fig. 8K,L), which itself is also absent in homozygous mutant mice (Fig. 8N). In contrast, no abnormalities were detectable in the musculature of the forelimbs of mutant mice (data not shown).

\section{Discussion}

In this study we have analyzed the developmental role of Pax9 in vivo. The phenotype of homozygous Pax9lacz mouse mutants revealed an essential function of this gene in the development of a wide range of organs and skel etal el ements (Table 1). Pax9 is required for the formation of thymus, parathyroid glands, and ultimobran- chial bodies, organs of endodermal origin. An essential role of Pax9 in organs derived from neural crest mesenchyme was shown by the absence of teeth and the formation of a cleft secondary palate in Pax9-deficient mice. Skeletal defects at the base of the skull indicate an involvement of Pax9 in the development of derivatives of the prechordal plate mesoderm. Finally, in the limbs Pax9 is required for normal development of the skel eton and musculature, which are formed by the lateral plate and paraxial mesoderm, respectively. Thus, Pax9 is a key regulator of organogenesis at diverse sites of the mammalian embryo, and its function is neither restricted to a specific germ layer nor to a specific cell type.

\section{The role of Pax9 during tooth development}

In the mesenchyme of the first branchial arch, the level of Pax9 expression is highest in the immediate vicinity of the epithelia, suggesting an involvement of Pax9 in epithelial-mesenchymal interactions (Neubüser et al. 1997). During tooth development, FGF8, a member of 


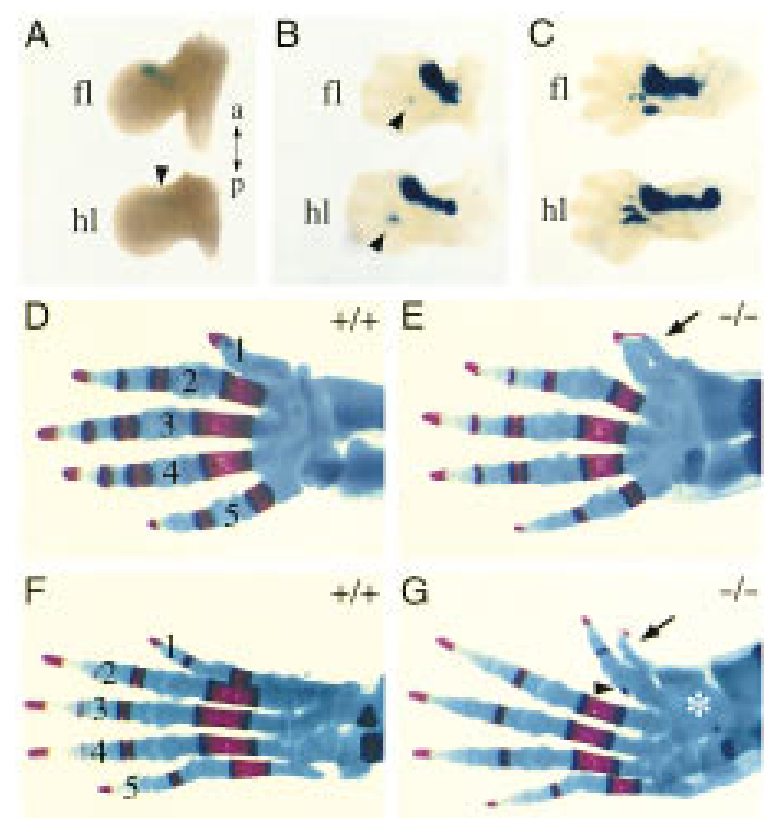

Figure 7. Preaxial digit duplications of hind- and forelimb in Pax9-deficient mice. $(A, B, C)$ Paxg ${ }^{\text {lacz }}$ expression during limb development in heterozygous Paxglacz mutants. The dorsal view of the left limbs is shown and the anterior-posterior $(a, p)$ axis is indicated. (A) At E11.5, PaxglacZ expression is seen in an anterior domain of the forelimb (fl) whereas at this stage the expression in the hindlimb (hl) is only weakly detectable (arrowhead). (B) At E12.5 the expression domain is elongated and expression starts in the region of the middle hand/foot. (C) Distinct patches of Pax ${ }^{\text {lacZ }}$ expression appear in the middle hand/ foot at E13.5 and the expression in both zeugopods is maintained. (D-G) Skel etal stainings of the left fore $(D, E)$ and hindlimbs $(F, G)$ of newborn wild-type $(D, F)$ and homozygous Paxglacz mutants $(E, G)$. Dorsal views are shown and the digits are numbered. (E) In the forelimb the extra-formed digit (arrow) is not separated from the thumb. (G) In the hindlimb of homozygous Paxglacz mutants the duplication of the first digit (arrow) is accompanied by an enlarged cartilaginous area in the region of the anterior metatarsals (asterisk). $\mathrm{N}$ ote al so the abnormal ossification center in the first toe (arrowhead).

the fi broblast growth factor family is expressed in a wide area of the oral epithelium and has been suggested to be the endogenous inducer of Pax9 expression in mandibular arch mesenchyme. This induction is spatially restricted by BMP4 and/or BMP2, both members of the TGF $\beta$ growth factor family. Thus, antagonistic signaling of FGF8 and BM P4/ 2 is a potential mechanism for positioning the sites of tooth formation in vivo ( $N$ eubüser et al. 1997).

Our analysis shows that Pax9 is essential for tooth development to proceed beyond the bud stage. The first deviation in mutant tooth devel opment is a fai lure of the mesenchyme to condense around the epithelial bud. This phenotype is remarkably similar to that seen in Msx1-deficient mice (Satokata and Maas 1994). Msx I and Pax9 exhibit an overlapping expression pattern in tooth mesenchyme, raising the possibility that both genes act in the same developmental pathway. Experi- mental evidence indicated that Msx1 and Bmp4 expression in the dental mesenchyme are maintained through a positive feedback loop, which might be essential for tooth development to proceed from the bud to the cap stage (Chen et al. 1996). Our results show that this feedback loop is indeed affected in Pax9-deficient embryos: At the bud stage, the expression of Bmp4, Msx1, and Lef1 were found to be down-regulated in the tooth mesenchyme of homozygous Paxglacz mutants. Thus, at a critical stage of tooth development, Pax9 may act upstream of Bmp4, Msx1, and Lef1. Consistent with this idea, preliminary results indicate that mesenchymal Pax9 expression is not altered in Msx $\mathrm{I}^{-1-}$ or $\mathrm{Lef}^{-1-}$ mutant embryos $(\mathrm{H}$. Peters, unpubl.). Pax9 function might be required to induce the formation of the enamel knot by maintaining the expression of Bmp4, which was recently shown to be involved in enamel knot induction (Jernvall et al. 1998). The molecular mechanism of Pax9 function within this particular network remains to be resolved. Because the early Msxl expression (up to E12.0) is not affected in homozygous Pax ${ }^{l a c z}$ mutants, it is unlikely that Pax9 is involved in the transcriptional regulation of the Msx1 gene. Instead, from our data, we favor a model in which thelater decline of Msxl and Lef 1 expression in homozygous Pax9lacz mutants is caused by the absence of BM P4 at E13.5.

\section{Pax9 is required for secondary pal ate development}

A cleft secondary palate is one of the most frequent birth defects in humans and is generally attributed to a combination of genetic predisposition and environmental factors (M urray 1995; Thorogood 1997). Among environmental factors, certain teratogens such as retinoic acid, ethanol, 6-aminonicotinamide, as well as other substances have been identified as inducers of a cleft secondary palate (Sulik et al. 1988; Gorlin et al. 1990). Recently, it has been suggested that cleft secondary pal ate formation in mice induced by 6 -aminonicotinamide involves genes at the chromosomal region in which Pax9 is located (Diehl and Erickson 1997). Our anal ysis has provided genetic evidence that Pax9 is indeed essential for secondary palate formation, and we have shown that Pax9 is required to regul ate the normal shape of the pal atal shelves prior to shelf elevation. Therefore, our findings should help us to understand the effects of teratogens during secondary palate development on the molecular level.

\section{Lack of pharyngeal pouch derivatives}

In the absence of Pax9, all pharyngeal pouches are initiall ly formed but the devel opment of the third and fourth pouches is arrested at E11.5, leading to the lack of thymus, parathyroid glands, and ultimobranchial bodies. At this stage, not only Pax9, but also Pax1, is expressed in the epithelium of the third pharyngeal pouches, and it was shown that at later stages, Paxl expression in the thymic epithelium is required for normal T-cell maturation (Wallin et al. 1996). However, Paxl is apparently not able to compensate for the absence of Pax9 during the 


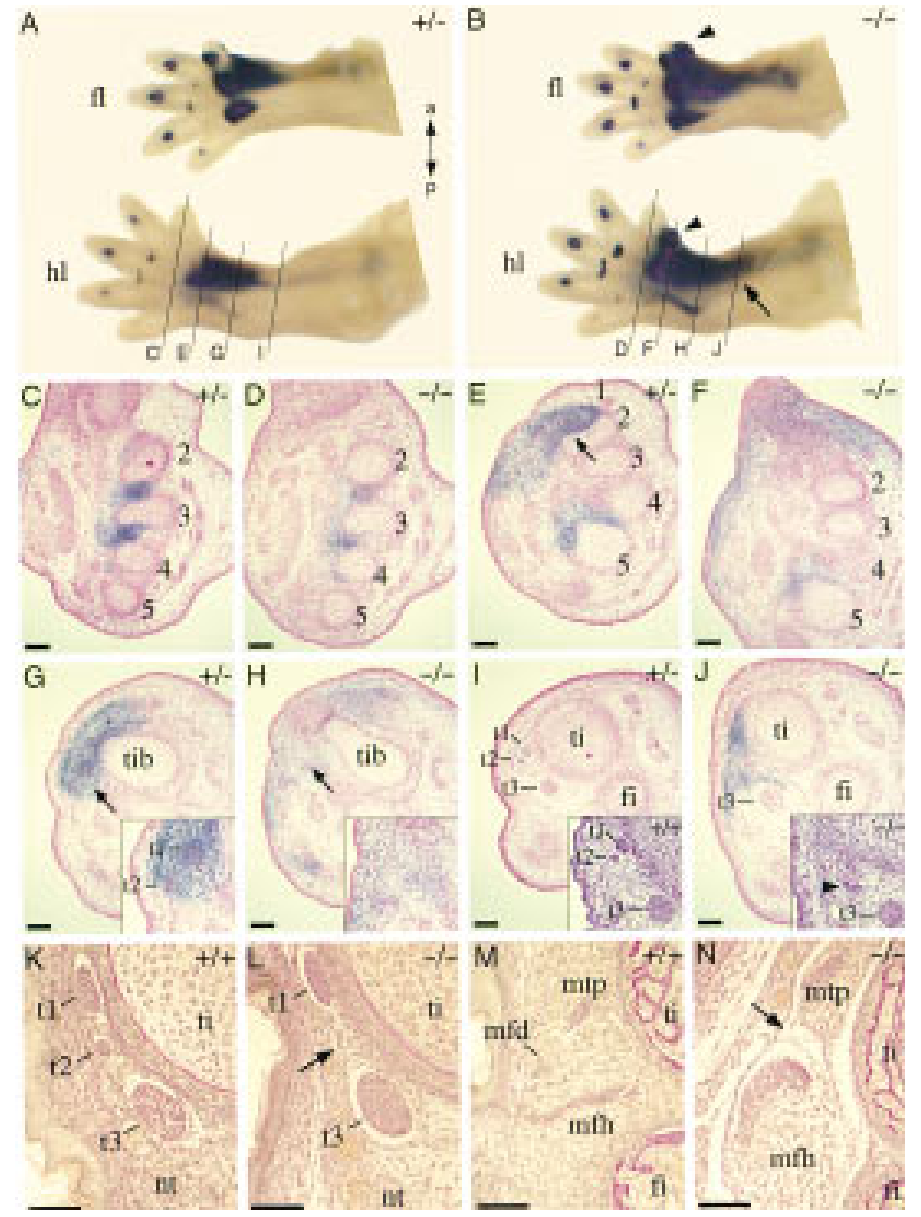

Figure 8. Analysis of the hindlimb defects of homozygous Paxglacz mutants. (A) Pax9 ${ }^{\text {lacz }}$ expression in the fore (fl) and hindlimb (hl) of a heterozygous Paxglacz mutant at E14.0. (B) Pax9 $9^{\text {lacz }}$ expression in a homozygous Pax $9^{\text {lacz }}$ littermate. $\mathrm{N}$ ote the strong expression in the developing extra-digits (arrowheads) and the proximally extended expression in the hindlimb (arrow). The level of sections in the panels shown below (C-J) are indicated in A and B. (C-J) Sections of X-gal-stained Pax9 mutant embryos (E14.0) counterstained with nuclear red. (C) At the level of the middle-foot expression of Paxglacz is restricted to the mesenchyme between the metatarsals (2-5). (D) A similar expression pattern is seen in the homozygous Pax $9^{\text {lacz }} \mathrm{mu}$ tant. At the proximal region of the metatarsals the anterior expression domain of PaxglacZ in the heterozygous mutant $(E)$ is restricted (arrow) to a specific region whereas in the absence of Pax9 $(F)$ the expression is distributed in a wide area of undifferentiated mesenchyme. (G) At the level of the tibiale (tib), the expression of Paxglacz covers the region of two developing tendons in the heterozygous Paxglacz mutant ( $t 1$ and $t 2$, see arrow and magnification in the inset). $(\mathrm{H})$ In the homozygous mutant the tendons are not detectable at this level (arrow). (I) At the distal end of the tibia, a group of three tendons ( $t 1, t 2, t 3)$ are detectable. $\mathrm{H} / \mathrm{E}$ staining confirmed the same arrangement of these tendons in a wild-type embryo (inset). (J) In contrast, in homozygous Pax9lacz mutants, only one tendon (arrowhead in inset) is detectable in the region of $\mathrm{t} 1$ and $\mathrm{t} 2$. N ote al so the ectopic expression of Paxglacz in the region where $\mathrm{t} 1$ and $\mathrm{t} 2$ normally develop. (K-N) Van Gieson staining of transverse sections through the hindlimbs of newborn mice. (K) At the level of the distal end of the tibia, three tendons (t1, t2, t3) are detectable in the wild-type mouse. (L) t2 is missing in the absence of Pax9 (arrow). (M) The musculus flexor digitorum ( $\mathrm{mfd}$ ), which is continuous to $\mathrm{t} 2$, is located between the musculus tibial is posterior ( $\mathrm{mtp}$ ) and the musculus flexor hallucis ( $\mathrm{mfh}$ ) and is absent in homozygous Paxglacz mutants (arrow in N). (t1) Tendon of musculus tibial is posterior; (t2) Tendon of musculus flexor digitorum; (t3) Tendon of musculus flexor hallucis. Bars, $100 \mu \mathrm{m}$. embryonic phase of thymus formation. Therefore, it is possible that Pax9 and Pax1 regulate different processes during pharyngeal pouch development. Alternatively, if a common set of target genes is postulated, a critical threshold of Pax9/Pax1 protein might be required during early thymus development.

Recently, an ectopic lymphoepithelial structure growing into the lumen of the oral cavity at the level of the developing larynx has been detected in Pax9-deficient mouse embryos (C. Egger and T. Boehm, pers. comm.). Experiments are under way to clarify the origin and developmental course of this structure, which could have an immunological function.

Experiments in chick have shown that interactions between neural crest cells and the pharyngeal pouch endoderm are required for thymus development (Le Douarin et al. 1984). This interaction may be affected in HoxA3deficient mice, which lack a thymus (Chisaka and $\mathrm{Ca}$ pecchi 1991). Interestingly, in HoxA 3 mutants, Pax1 expression in the third pharyngeal pouches is down-regulated (M anley and Capecchi 1995), rai sing the possibility that HoxA 3 regulates Pax9 as well. Abnormal neural crest development is believed to cause the absence of thymus and parathyroid in the human congenital disorder DiGeorge syndrome. The localization of the human PAX9 gene on chromosome 14 (Stapleton et al. 1993) excludes it as a primary gene affected in this syndrome. However, genes affected in DiGeorge syndrome may regulate Pax9 expression, or, alternatively, are regulated by Pax 9 during the development of thymus and parathyroid gl ands.

The parathyroid glands and ultimobranchial bodies regulate calcium homeostasis through the release of parathormone and calcitonin, respectively, and are therefore indispensable for the integrity of the skeleton. Although newborn homozygous Pax ${ }^{\text {lacz }}$ mutants lack both organs, the devel opment of long bones appeared not to be affected (data not shown). Si milarly, no defects in long bone formation have been reported in the aparathyroid HoxA3 knockout mouse (Chisaka and Capecchi 1991). These observations indicate that parathyroid glands and ultimobranchial bodies are not required for 
Table 1. Summary of Pax9 expression domains and observed phenotypes in homozygous Pax9lacz mutants

\begin{tabular}{|c|c|c|}
\hline Origin & Organ & Phenotype \\
\hline Endoderm & $\begin{array}{l}\text { eustachian tube } \\
\text { tonsils } \\
\text { thymus } \\
\text { parathyroid glands } \\
\text { ultimobr. bodies } \\
\text { oral epithelium, pharynx } \\
\text { salivary glands } \\
\text { esophagus, forestomach } \\
\text { trachea } \\
\text { tailgut }\end{array}$ & 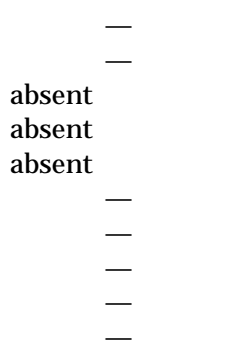 \\
\hline M esoderm & $\begin{array}{l}\text { processus alaris } \\
\text { pterygoid process } \\
\text { phalanges } \\
\text { middle foot } \\
\text { limb tendons/muscles } \\
\text { tail muscles } \\
\text { tongue muscles } \\
\text { intercostal tissue } \\
\text { vertebral column }\end{array}$ & $\begin{array}{l}\text { absent } \\
\text { malformed } \\
\text { digit duplication } \\
\text { malformed } \\
\text { absence of m.f.d. } \\
\quad- \\
- \\
- \\
-\end{array}$ \\
\hline Ectoderm & $\begin{array}{l}\text { oral epithelium } \\
\text { tongue epithelium } \\
\text { taste buds } \\
\text { tegmentum } \\
\text { mammillary bodies }\end{array}$ & $\begin{array}{l}- \\
- \\
- \\
-\end{array}$ \\
\hline Neural crest & $\begin{array}{l}\text { nasal mesenchyme } \\
\text { palatine, maxilla } \\
\text { teeth } \\
\text { coronoid process } \\
\text { tympanic ring } \\
\text { Reicherts cartilage } \\
\text { hyoid bone } \\
\text { thyroid cartilage } \\
\text { cricoid cartilage }\end{array}$ & $\begin{array}{l}\text { cleft palate } \\
\text { absent } \\
\text { absent } \\
\text { malformed* } \\
\text { malformed* } \\
\text { malformed } \\
\text { malformed } \\
\text { malformed }\end{array}$ \\
\hline
\end{tabular}

Organs are grouped according to the embryonic origins of Pax9expressing structures. $\mathrm{N}$ ote that cells derived from other germ layers typically also contribute to the formation of a given organ/structure. The phenotypes developed with 100\% penetrance if not indicated otherwise. At least eight homozygous Pax9lacz mutants were analyzed for each phenotype. $\left(^{*}\right)$ In these organs, malformations did not show full penetrance; $60 \%$ ( $n=$ 26) of homozygous Pax ${ }^{\text {lacz }}$ mutants exhi bited a mal formed tympanic ring; 3 of 26 homozygous Pax ${ }^{\text {lacz }}$ mutants developed a continuous skeletal element between middle ear and hyoid bone, whereas in the remaining homozygous mutants Reicherts cartilage was absent. (m.f.d.) musculus flexor digitorum; (-) Phenotypic abnormalities were not detected (for details, see text).

I ong bone development during embryonic and fetal periods.

\section{Skel etal defects}

Pax9 and the closely related paralogous gene Paxl exhibit a similar expression pattern during the development of the vertebral column. The lack of an obvious phenotype in the vertebral column in Pax9lacz mutants suggests that here the loss of Pax9 function is rescued by Pax1. In double mutant mice lacking both Pax9 and Pax1 the vertebral col umn is more severely affected than in Paxl mutants ( $H$. Peters and R. Balling, unpubl.), indicating a redundancy of Pax9 and Paxl in this part of the skeleton.

In the vertebrate limb the establishment of the anterior-posterior axis is controlled by a group of cells located in the posterior limb mesenchyme (for review, see Tickle and Eichele 1994), the zone of polarizing activity (ZPA). A key molecule secreted by the ZPA is Sonic Hedgehog (SHh), which is sufficient to mimic the ZPA when ectopically expressed in the anterior limb mesenchyme (Riddle et al. 1993). Recently, it was shown that in SHh-deficient mice Paxl expression in the somites is rapidly lost, whereas the expression is not al tered in the anterior limb mesenchyme (Chiang et al. 1996). In both domains, Pax 1 and Pax9 exhibit a similar expression pattern, raising the possibility that Pax 9 might be regulated by SHh in similar ways. In contrast to the ZPA, little is known about the role of the anterior mesenchyme in patterning the anterior-posterior axis of the limb. Alx-4, a transcription factor containing a paired-type homeodomain, is specifically expressed in the anterior mesenchyme and the absence of Alx-4 was shown to cause preaxial digit duplications. It was suggested that $A \mid x-4$ is involved in the repression of an anterior ZPA activity, whose presence might have been the default stage in the limbs of primitive vertebrates (Qu et al. 1997). In fact, in most polydactyly mutants, ectopic expression of $\mathrm{SHh}$ was found (for review, see Cohn and Tickle 1996). Pax9 might play a similar role to that of Alx-4, however, in Pax9 mutants, the phenotype of the digits is mild and the absence of Pax9 affects other anterior regions of the limbs as well. Eventually, the identification of Pax9 target genes are required to understand the role of Pax9 during limb development.

Pax9 deficiency also leads to specific skeletal defects during craniofacial devel opment (Table 1). Whereas the affected structures of the skull correl ate with the embryonic expression of Pax9 in the corresponding region, most of the defects seen in the laryngeal cartilages do not. In the latter, Pax $9^{\text {lacz }}$ expression was only found in the mesenchyme surrounding Reicherts cartilage while we were not ableto detect expression in the precursors of the hyoid and thyroid cartilages. Therefore, we suggest that skeletal malformations in the laryngeal cartilages are caused indirectly, that is, by a failure of interaction with the pharyngeal endoderm. Indeed, tissue recombination studies have indicated that the pharyngeal endoderm is required for cartilage formation of branchial arch-derived mesenchyme in a contact-dependent manner (Hörstadius and Sellman 1946; Epperlein and Lehmann 1975). The severely malformed pharyngeal pouch epithel ium of homozygous Paxglacz mutants may thus explain the skel etal defects of the laryngeal cartilages. However, the mechanisms leading to these defects are presently unclear. Normal pharyngeal epithelium might not only promote cartilage formation in the neighboring mesenchyme, it could also provide positional 
information that is required to pattern the laryngeal cartilages.

Not all Pax9 expression domains are affected in the mutants

By gross morphological inspection and histological criteria, some organs and structures that express Pax9 during embryonic development appeared normal in Pax9deficient newborn mice. These include the salivary glands and the epithel ia lining the upper di gestive tract. Similarly, no abnormalities were detected in the tail, knee, el bow, in intercostal tissue, in the tongue, and in the brain (Table 1, and data not shown). These results may indicate that Pax9 function is not required in all of its expression domains. However, it should be noted that some of these organs are not yet completely differentiated in newborn mice. In particular, this status appl ies to the epithelial lining of the upper digestive tract (tongue, oral cavity, pharynx, esophagus, and forestomach), which still expresses Pax9 in the adult (Peters et al. 1997). Similarly, Pax9 could play a role in the development of the hypothalamic mammillary body. Recently, it was shown that thelack of Fkh5, which is expressed in the mammillary body, leads to disturbed feeding and drinking behavior (Labosky et al. 1997; Wehr et al. 1997). Thus, in some organs, Pax9 could have essential functions after birth; however, an analysis is precluded by the early death of mutant pups.

\section{Materials and methods}

\section{Generation of Pax9-deficient mice}

A mouse genomic library from 129 /Sv mice was screened with a Pax9 CDNA probe containing the paired box of Pax9 (Neubüser et al. 1995). Three overlapping phage cl ones were isol ated, which together cover $19.5 \mathrm{~kb}$ of genomic DN A containing the start codon and the paired box exon of the Pax9 gene. A 2.0-kb BglII-EcoRI fragment was cloned into the BamHI-EcoRI site of the PGK-neo and PGK-tk containing vector pPNT (Tybulewicz et al. 1991). In the resulting plasmid (pPax9-1), the neo gene and the tk gene have the same $5^{\prime} \rightarrow 3^{\prime}$ direction as the Pax9 gene. A 4.7-kb Xmal fragment containing parts of the $5^{\prime}$-untranslated region of the Pax9-cDN A was then cloned into the Xmal site of pATG-lacZ (pPax9-2). The final targeting vector was constructed first by cloning of the upstream 1.0-kb Xmal-Xhol fragment of pPax9-2 into the Xhol site of pPNT containing pPax9-1 to generate pPax9-3. Finally, a 7.2-kb Xhol fragment of pPax9-2 containing the major part of the future long arm of the targeting construct fused to the lac $Z$ cassette was released and ligated into the same Xhol site to generate the targeting vector pPax9-4. The targeting vector $(100 \mu \mathrm{g})$ was linearized with $\mathrm{N}$ otl and electroporated into R1 ES cells ( $N$ agy et al. 1993) and selected with G418/gancyclovir as described (Wurst and Joyner 1993). Integrations of the targeting vector via homologous recombination were identified by Southern bl ot analysis of genomic DN A from resistant ES cell clones with an external probe from the $5^{\prime}$ region of the targeted Pax9 locus using standard protocols (Wurst and Joyner 1993). Two chimeras obtained by injection of correctly targeted ES cell clones into C57BL/ 6 blastocysts yiel ded germ-line transmission. Pax9-deficient offspring from both lines exhibited the same phenotype. Genotyping of embryos obtained from heterozygous crosses was performed by PCR with one primer (5'-TTCAGCCGGGCACAGACTTCC-3', forward) present in the $5^{\prime}$-untranslated region of the Pax 9 CDN A and two allele-specific reverse primers (5'-GCTGGTTCACCTCCCCGAAGG-3', Pax9 ${ }^{\text {wt }}$; and 5'-CGAGTGGCAACATGGAAATCGC-3', Pax9lacz) in one reaction. The resulting 950-bp fragment represents the wild-type Pax9 allele, whereas the 900-bp fragment was amplified from the Pax $9^{l a c z}$ allele. Chimeras were mated to C57BL/ 6 mice, and the Pax ${ }^{\text {lacz }}$ allele was propagated on $\mathrm{C} 57 \mathrm{BL} / 6$ genetic background. Offspring from generations $\mathrm{F}_{2^{-}}$ $F_{6}$ were used in this study.

\section{X-Gal staining and immunostaining}

Whole-mount Paxglacz mutant embryos were stained with $X$ gal for 8-12 hr according to established protocols (Gossler and Zachgo 1993). For sections, X-gal-stained tissue was embedded in paraffin, serially sectioned at $7 \mu \mathrm{m}$, and counterstained with Nuclear Red. To completely visualize Pax9lacz expression, some embryos were dehydrated in methanol and cleared with benzyl benzoate/ benzylal cohol.

Pax9-specific polyclonal antibodies (281-IV) were obtained from rabbits immunized with a maltose-binding protein (Guan et al. 1987) fused to the 90 carboxy-terminal amino acids of the murine Pax9 protein according to established protocols (Harlow and Lane 1988). Detection of Pax9 protein in 30- $\mu$ g protein extracts prepared from the vertebral column of E13.5 embryos by Western blot analysis was performed as described (Peters et al. 1995). After washing, the membranes were incubated with sheep anti-rabbit IgG-alkal ine phosphate conjugate (Boehringer Mannheim, Germany), and recognized proteins were visualized by staining with NBT and X-phosphate. Whole-mount immunostainings with HoxB1-specific antibodies (BAbCO, Richmond, USA) were performed as described ( $M$ anley and Capecchi 1995).

\section{Tissue recombination}

Tissue recombination experiments with dental epithelium and dental mesenchyme from timed E13.5 embryos were carried out as described previously (Kratochwil et al. 1996). Briefly, molar rudiments were dissected from the lower jaws. Tooth mesenchyme and epithelium were separated in $0.1 \%$ collagenase at $37^{\circ} \mathrm{C}$. For recombination, mesenchyme and epithelium were placed on Nuclepore membrane filters and subsequently cultured for 2 days in vitro and for 11 days more under the kidney capsule of adult mice. Although homozygous Paxglacz embryos can be identified because of impaired epithelial devel opment of the incisors, the genotypes of all embryos were determined by PCR analysis. Heterozygous and wild-type embryos served as donors for normal tissue.

\section{Histological procedures and in situ hybridization}

For histological analysis and in situ hybridizations, tissues were fixed in $4 \%$ paraformal dehyde, dehydrated in isopropanol, and embedded in paraffin. Serial sections at $7 \mu \mathrm{m}$ were stained with hematoxylin/eosin (H/E) or after Van Gieson. Explanted tissues from recombination experiments were fixed in Bouin's solution. After being embedded in paraffin, they were cut at $7 \mu \mathrm{m}$ and stained with Azan stain. In situ hybridization on sections was performed as described (Peters et al. 1995; N eubüser et al. 1995). To optimize a comparative expression analysis in the tooth mesenchyme, embryos of one litter were used in parallel for fixation, dehydration, and embedding. Furthermore, frontal sections of wild-type and mutant embryos representing similar anatomical levels were collected on one slide and hybridized simultaneously.

Skeletal staining of cartilage and bone was performed with alcian blue and alizarin red as described (Kessel et al. 1990). 


\section{Acknowledgments}

We thank R. Grosschedl, M. Nister, and R. Zeller for providing DNA probes and M. Schieweg for technical assistance. We thank $C$. Egger and T. Boehm for pointing out the presence of the Iymphoepithelial structure in the Iarynx of Pax9-deficient mouse embryos. We also thank K. Pfeffer for blastocyst injection, A. Luz for help with histological analysis, and J. Rossant for the vectors PPNT and PATG-lacZ, and for the genomic library of $129 / \mathrm{Sv}$ mice. We are grateful to R. M aas and R. Grosschedl for providing homozygous $\mathrm{Msx}^{-1-}$ and Lef $1^{-1-}$ mutant embryos, respectively, and to R. Spörle, B. Wilm, and U. Dietz for critical reading of the manuscript. This work was supported by the DFG (Deutsche Forschungsgemeinschaft).

The publication costs of this article were defrayed in part by payment of page charges. This article must therefore be hereby marked "advertisement" in accordance with 18 USC section 1734 solely to indicate this fact.

\section{References}

Baumgartner, S., D. Bopp, M. Burri, and M . N oll. 1987. Structure of two genes at the gooseberry locus related to the paired gene and their spatial expression during embryogenesis. Genes \& Dev. 1: 1247-1267.

Bopp, D., M. Burri, S. Baumgartner, G. Frigerio, and M. Noll. 1986. Conservation of a large protein domain in the segmentation gene paired and in functionally related genes of Drosophila. Cell 47: 1033-1040.

Chalepakis, G., A. Stoykova, J. Wijnholds, P. Tremblay, and P. Gruss. 1993. Pax: Gene regulators in the developing nervous system. J. Neurobiology 24: 1367-1384.

Chen, Y.P., M. Bei, I. Woo, I. Satokata, and R. M aas. 1996. Msx1 controls inductive signaling in mammalian tooth morphogenesis. Development 122: 3035-3044.

Chiang, C., Y. Litingtung, E. Lee, K.E. Young, J.L. Corden, H. Westphal, and P.A. Beachy. 1996. Cyclopia and defective axial patterning in mice lacking Sonic hedgehog gene function. Nature 383: 407-413.

Chisaka, O. and M. Capecchi. 1991. Regionally restricted developmental defects resulting from the targetted disruption of the mouse homeobox gene hox1.5. Nature 350: 473-479.

Cohn, M.J. and C. Tickle. 1996. Limbs: A model for pattern formation within the vertebrate body plan. Trends Genet. 12: 253-257.

Dahl, E., H. Koseki, and R. Balling. 1997. Pax genes and organogenesis. Bioessays 19: 755-765.

Deutsch, U., G.R. Dressler, and P. Gruss. 1988. Pax1, a member of a paired box homologous murine gene family, is expressed in segmented structures during development. Cell 53: 617625.

Diehl, S.R. and R.P. Erickson. 1997. Genome scan for teratogeninduced cl efting susceptibility loci in the mouse: Evidence of both allelic and locus heterogeneity distinguishing cleft lip and cleft palate. Proc. Natl. Acad. Sci. 94: 5231-5236.

Epperlein, H.H. and R. Lehmann. 1975. The ectomesenchymalendodermal interaction system (EEIS) of Triturus al pestris in tissue culture. 2. Observation on the differentiation of visceral cartilage. Differentiation 4: 159-174.

Frohman, M., M. Boyle, and G.R. M artin. 1990. Isolation of the Hox-2.9 gene: Analysis of embryonic expression suggests that positional information along the anterior-posterior axis is specified by mesoderm. Development 110: 589-607.

Gorlin, R.J., M.M. Cohen, and L.S. Levine. 1990. Syndromes of the head and neck, 3rd ed. Oxford University Press, N ew York, NY.
Gossler, A. and J. Zachgo. 1993. Gene and enhancer trap screens in ES cell chimeras. In Gene targeting: A practical approach (ed. A.L. Joyner), pp. 181-227. Oxford University Press, N ew York, NY.

Greene, R.M. and R.M. Pratt. 1976. Developmental aspects of secondary palate formation. J. Embryol. Exp. Morphol. 36: 225-245.

Guan, C., P. Li, P.D. Riggs, and H. Inouye. 1987. Vectors that facilitate the expression and purification of foreign proteins in Escherichia coli by fusion to maltose-binding protein. Gene 67: 21-30.

Harlow, E. and D. Lane. 1988. Antibodies: A laboratory manual. Cold Spring Harbor Laboratory, Cold Spring Harbor, NY.

Hörstadius, S. and S. Sellman. 1946. Experimentelle Untersuchungen über die Determination des knorpeligen Kopfskelettes bei Urodelen. Nova Acta R. Soc. Scient. U psal. 13: 1170.

Jernvall, J., T. A berg, P. Kettunen, S. Keränen, and I. Thesl eff. 1998. The life history of an embryonic signaling center: BM P-4 induces p21 and is associated with apoptosis in the mouse tooth enamel knot. Development 125: 161-169.

Kessel, M., R. Balling, and P. Gruss. 1990. Variations of cervical vertebrae after expression of a Hox-1.1 transgene in mice. Cell 61: 301-308.

Kratochwil, K., M. Dull, I. Fariñas, J. Galceran, and R. Grosschedl. 1996. Lef1 expression is activated by BM P-4 and regulates inductive tissue interactions in tooth and hair development. Genes \& Dev. 10: 1382-1394.

Labosky, P.A., G.E. Winnier, T.L. Jetton, L. Hargett, A.K. Ryan, M.G. Rosenfel d, A.F. Parlow, and B.L.M. Hogan. 1997. The winged helix gene, $\mathrm{Mf3}$, is required for normal development of the diencephalon and midbrain, postnatal growth and milk-ejection reflex. Development 124: 1263-1274.

Le Douarin, L.M., F. Dieterlen-Lievre, and P.D. Oliver. 1984. Ontogeny of primary lymphoid organs and Iymphoid stem cells. Am. J. Anat. 170: 261-299.

Lumsden, A.G. 1988. Spatial organization of the epithelium and the role of neural crest cells in the initiation of the mammalian tooth germ. (Suppl.) Development 103: 155-169.

Manley, N.R. and M.R. Capecchi. 1995. The role of Hoxa-3 in mouse thymus and thyroid development. Development 121: 1989-2003.

Mina, M. and E.J. Kollar. 1987. The induction of odontogenesis in non-dental mesenchyme combined with early murine mandibular arch epithelium. Arch. Oral Biol. 32: 123-127.

Murray, J.C. 1995. Face facts: Genes, environment, and clefts. Am. J. Hum. Genet. 57: 227-232.

N agy, A., J. Rossant, R. N agy, W. Abramow-N ewerly, and J.C. Roder. 1993. Derivation of completely cell culture-derived mice from early-passage embryonic stem cells. Proc. Natl. Acad. Sci. 90: 8424-8428.

N eubüser, A., H. Koseki, and R. Balling. 1995. Characterization and devel opmental expression of Pax9, a paired-box-containing gene related to Pax1. Dev. Biol. 170: 701-716.

N eubüser, A., H. Peters, R. Balling, and G. Martin. 1997. Antagonistic interactions between FGF and BMP signaling pathways: A mechanism for positioning the sites of tooth formation. Cell 90: 247-255.

Nornes, S., I. Mikkola, S. Krauss, M. Delghandi, M. Perander, and T. Johansen. 1996. Zebrafish Pax9 encodes two proteins with distinct $\mathrm{C}$-terminal transactivating domains of different potency negatively regulated by adjacent $\mathrm{N}$-terminal sequences. J. Biol. Chem. 271: 26914-26923.

Peters, H., U. Doll, and J. Niessing. 1995. Differential expression of the chicken Pax-1 and Pax-9 gene: In situ hybridiza- 
tion and immunohistochemical analysis. Dev. Dyn. 203: 1-16.

Peters, H., G. Schuster, A. N eubüser, T. Richter, H. Höfler, and R. Balling. 1997. Isolation of the PAX9 CDNA from adult human esophagus. Mammal. Genome 8: 62-64.

Qu, S., K.D. N iswender, Q. Ji, R. van der M eer, D. Keeney, M .A. Magnuson, and R. Wisdom. 1997. Polydactyly and ectopic ZPA formation in Alx-4 mutant mice. Development 124: 3999-4008.

Riddle, R.D., R.L. Johnson, E. Laufer, and C. Tabin. 1993. Sonic hedgehog mediates the polarizing activity of ZPA. Cell 75: 1401-1416.

Satokata, I. and R. Maas. 1994. Msx-1 deficient mice exhibit cleft palate and abnormalities of craniofacial and tooth development. N ature Genet. 6: 348-356.

Stapleton, P., A. Weith, P. Urbanek, Z. Kozmik, and M. Busslinger. 1993. Chromosomal localisation of seven Pax genes and cloning of a novel family member, Pax9. Nature Genet. 3: 292-304.

Sulik, K.K., C.S. Cook, and W.S. Webster. 1988. Teratogens and craniofacial malformations: Relationships to cell death. (Suppl.) Development 103: 213-232.

Thesl eff, I. and P. Sharpe. 1997. Signalling networks regulating dental development. Mech. Dev. 67: 111-123.

Thorogood, P. 1997. The head and face. In Embryos, genes, and birth defects (ed. P. Thorogood), pp. 197-224. John Wiley \& Sons, Chichester, UK.

Tickle, C. and G. Eichele. 1994. Vertebrate limb development. Annu. Rev. Cell. Biol. 10: 121-152.

Timmons, P., J. Wallin, P.W.J. Rigby, and R. Balling. 1994. Expression and function of Pax1 during development of the pectoral girdle. Development 120: 2773-2785.

Tybulewicz, V.L., C.E. Crawford, P.K. Jackson, R.T. Bronson, and R.C. Mulligan. 1991. N eonatal lethal ity and lymphopenia in mice with a homozygous disruption of the c-abl protooncogene. Cell 65: 1153-1163.

Vaahtokari, A., T. A berg, J. Jernvall, S. Keränen, and I. Thesl eff. 1996. The enamel knot is a signalling center in the developing mouse tooth. Mech. Dev. 54: 39-43.

Vainio, S., I. Karavanova, A. Jowett, and I. Thesl eff. 1993. Identification of BM P-4 as a signal mediating secondary induction between epithelial and mesenchymal tissues during early tooth development. Cell 75: 45-58.

Van Genderen, C., R.M. Okamura, I. Fariñas, R.G. Quo, T.G. Parslow, L. Bruhn, and R. Grosschedl. 1994. Development of several organs that require inductive epithelial-mesenchymal interactions is impaired in Lef-1-deficient mice. Genes \& Dev. 8: 2691-2703.

Wallin, J., H. Koseki, K. Imai, K. Moriwaki, N. Miyshita, and R. Balling. 1993. Pax-9, a new Pax-gene, maps to mouse chromosome 12. Mammal. Genome 4: 354-358.

Wallin, J., H. Eibel, A. N eubüser, J. Wilting, H. Koseki, and R. Balling. 1996. Paxl is expressed during development of the thymus epithelium and is required for normal T-cell maturation. Development 122: 22-30.

Walther, C., J.L. Guenet, D. Simon, U. Deutsch, B. Jostes, M.D. Goulding, D. Plachov, R. Balling, and P. Gruss. 1991. Pax: A multigene family of paired box-containing genes. Genomics 11: 424-434.

Wehr, R., A. M ansouri, T. de M aeyer, and P. Gruss. 1997. Fkh5deficient mice show dysgenesis in the caudal midbrain and hypothalamic mammillary body. Development 124: 44474456.

Wurst, W. and A.L. Joyner. 1993. Production of targeted embryonic stem cell clones. In Gene targeting: A practical approach (ed. A.L. Joyner), pp. 33-61. Oxford University Press, N ew York, NY. 


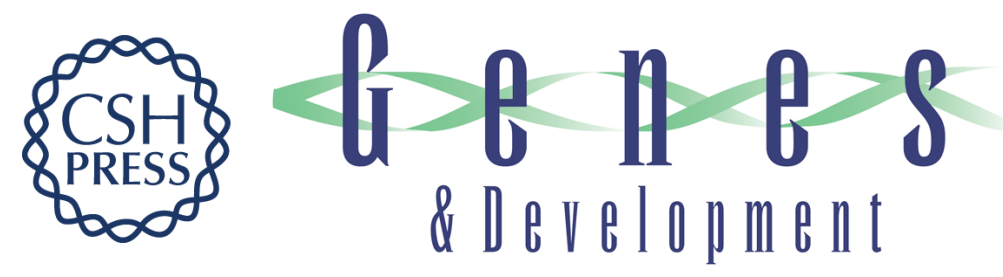

\section{Pax9-deficient mice lack pharyngeal pouch derivatives and teeth and exhibit craniofacial and limb abnormalities}

Heiko Peters, Annette Neubüser, Klaus Kratochwil, et al.

Genes Dev. 1998, 12:

Access the most recent version at doi:10.1101/gad.12.17.2735

\section{License}

Email Alerting

Service

Receive free email alerts when new articles cite this article - sign up in the box at the top right corner of the article or click here.

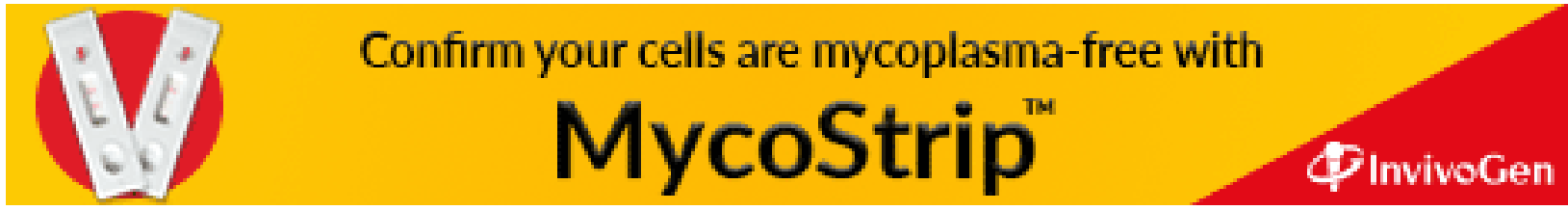

